Binz, C., Truffer, B., Li, L., shi, Y., \& Lu, Y. (2012). Conceptualizing leapfrogging

with spatially coupled innovation systems: the case of onsite wastewater treatment in

China. Technological Forecasting and Social Change, 79(1), 155-171.

https://doi .org/10.1016/j.techfore.2011.08.016

This manuscript version is made available under the CC-BY-NC-ND 4.0

1icense http://creativecommons.org/1icenses/by-nc-nd/4.0/

Paper re-submitted to Technological Forecasting and Social Change

\title{
Conceptualizing leapfrogging with spatially coupled innovation systems: The case of onsite wastewater treatment in China
}

\author{
Christian Binz ${ }^{\mathrm{a}}$, Bernhard Truffer ${ }^{\mathrm{b}}$, Li Lic, Yajuan Shic, Yonglong Lu ${ }^{\mathrm{c}}$

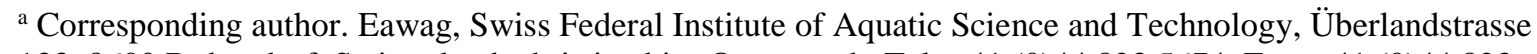 \\ 133, 8600 Dübendorf, Switzerland. christian.binz@eawag.ch. Tel: +41 (0)44 823 5674, Fax: +41 (0)44 823 \\ 5375. \\ ${ }^{b}$ Eawag, Swiss Federal Institute of Aquatic Science and Technology, Überlandstrasse 133, 8600 Dübendorf, \\ Switzerland. bernhard.truffer@eawag.ch. \\ c State Key Laboratory of Urban and Regional Ecology, Research Center for Eco-Environmental Sciences, \\ Chinese Academy of Sciences, Beijing 100085, China. yllu@rcees.ac.cn
}

\begin{abstract}
A rapid implementation of potentially more sustainable sector structures in newly industrializing countries (NICs) is of key importance to reach global sustainability. The conceptual basis for assessing such "leapfrogging” potentials is however still rather weakly developed. The present paper elaborates an encompassing conceptual framework drawing on the technological innovation systems literature and adding an explicit geographical focus that embeds an NIC's innovation system in its international context. From this, we derive six ideal-type leapfrogging trajectories. The framework is applied to the case of a potential transition to onsite wastewater treatment in China. Empirical evidence is based on 30 expert interviews with representatives from companies, universities, authorities and associations in China and Europe. Our results suggest that leapfrogging in the Chinese wastewater sector might develop in either an integrated "international innovation system" trajectory, where Chinese and international actors closely interact, or in an "international competition" trajectory, where Chinese actors endogenously build up technological leadership in strong competition to international actors. We conclude by outlining policy implications and by discussing future research priorities for leapfrogging and transition studies.
\end{abstract}

Keywords: Leapfrogging, Technological innovation system, Onsite wastewater treatment, Geography of transition, China, MBR technology 


\section{Introduction}

The fast economic expansion of newly industrializing countries (NICs) ${ }^{1}$ increasingly raises concerns about existing and future global environmental problems. As NICs often follow the technological trajectories of industrialized countries, they risk reproducing the same "carbon lock-in economy" [1, 2]. The academic literature on global environmental problems and on technological change is thus increasingly concerned with the question if and under which conditions a "sustainability transition" towards alternative and more sustainable development paths could be possible in NICs [3-7]. A major inquiry within this realm is whether NICs will be able to jump over (leapfrog) conventional, carbon-intensive development steps and directly implement radical system alternatives that are ecologically, economically and socially more sustainable [3, 6, 8-11]. Whether and under which conditions such a leapfrogging would be possible is highly contested.

Two academic traditions could potentially provide support for analyzing these questions: literature on leapfrogging and on sustainability transitions. Sustainability transitions research, however, is not yet well equipped for analyzing leapfrogging potentials as it has mostly focused on sector transformations within industrialized countries [12]. Transitions researchers would have to take into account that leapfrogging trajectories have to develop in the particular institutional $^{2}$ environments of the different NICs [5, 11]. Furthermore, NICs are embedded into increasingly internationalized knowledge networks and institutional structures [4, 5].Transition research has not yet developed concepts for assessing such international structures and processes.

Leapfrogging literature, on the other hand, is still rather embryonic and has not yet developed a coherent conceptual basis for prospective analysis. An often-cited example of leapfrogging is mobile telephony, which was established as the dominant regime of voice communication in many NICs, skipping a fixed-net telephony system [13-16]. Other recent leapfrogging studies cover the automobile industry [10,17, 18], semiconductor industries [8], the wind turbine industry [19], or information and communication technologies [13]. Most of these studies focus on well-established technologies and are based on somewhat simplistic assumptions and vague conceptualizations [9]. Leapfrogging is often analyzed from a relatively mechanistic economic or technological point of view. We argue that this is too narrow a focus, as environmental innovations typically develop in new, emerging industries and in a complex socio-technical system context. In addition, leapfrogging potentials in NICs depend on knowledge, actors and resources that are located outside the respective NICs [8]. The analysis of the international influence on leapfrogging potentials has often been limited to transnational corporations' activities and the effects of foreign direct investment (for an overview, see [9]). The influence of increasingly globalized actors and international associations and institutions has not yet been included into leapfrogging debates.

The present paper, therefore, aims at elaborating a conceptual framework for leapfrogging analysis based on a socio-technical systems perspective, and at developing and empirically illustrating a respective typology of leapfrogging trajectories that will enable a spatially explicit analysis. More specifically, we propose to conceptualize leapfrogging processes in the context of recent sustainability transitions literature [20], which analyzes radical transformations in specific economic sectors as a set of co-developing socio-technical reconfigurations. The respective analytical framework is based on the technological innovation systems perspective [21]. We explicitly differentiate between innovation systems structures in the national context of the NIC and the structures prevailing on an international

\footnotetext{
${ }^{1}$ Examples for NICs: China, India, Brazil, South Africa, Mexico, Turkey, Malaysia, Thailand.

${ }^{2}$ We apply a rule-centered definition of "institution" in this article, which includes all sorts of regulative, normative and cognitive institutions, such as laws, regulations, behavioral norms, ways of doing things, routines, belief systems, or guiding principles.
} 
level, while at the same time illustrating the couplings between national and international innovation system structures. With this basic geographic distinction, the paper contributes to the emerging literature on the "geography of transitions," i.e., how to assess innovation systems that extend beyond national borders [22-24] in a geographically explicit way [12, 25, 26].

The framework is applied to the Chinese urban wastewater sector, which exemplifies the infrastructure dilemma of many NICs. The sustainability of large net-bound infrastructures is increasingly questioned, particularly in water-scarce and rapidly urbanizing regions [27-29]. If the building of infrastructure is based exclusively on conventional, centralized wastewater technologies (the dominant design in industrialized countries), the creation of path dependencies prevents the future implementation of potentially more sustainable alternatives brought about through recent technological developments. For instance, more decentralized system configurations allow for closed water recycling loops inside individual buildings. In this article, we analyze potential leapfrogging trajectories of one such innovative wastewater recycling technology: small-scale membrane bioreactor (MBR) wastewater treatment plants. ${ }^{3}$

The central research question of this paper is as follows: How can future leapfrogging trajectories in NICs be analyzed from a space-sensitive innovation systems perspective? The answer to this question is developed in five steps: In the next section, the potential benefits of applying a technological innovation system perspective to leapfrogging are discussed. Based on this background, we define a typology of six ideal-type leapfrogging trajectories. Section 4 elaborates the methodology and section 5 applies our framework to a case study in the Chinese wastewater sector. Our results indicate that two leapfrogging trajectories are most likely: a) "international competition", where Chinese and international actors closely interact and b) "international innovation system", where Chinese actors endogenously build up technological leadership in strong competition to international actors. In the discussion and concluding sections, we critically discuss our results, suggest future improvements of the analytical framework and derive policy implications.

\section{Conceptualizing leapfrogging in an innovation system context}

\subsection{The need for a systemic perspective on leapfrogging}

Leapfrogging in NICs is increasingly perceived as a development option for mitigating global environmental change [30]. Nonetheless, the frequent use of this term stands in sharp contrast to the weak theoretical background in leapfrogging literature and the lack of a conceptual basis for assessing past or future leapfrogging developments [31]. The specific meaning of "leapfrogging" is often not even defined. In this article, we follow Tukker ([11]: 66), defining leapfrogging as a situation in which a NIC learns from the mistakes of developed countries and directly implements more sustainable systems of production and consumption, based on innovative and ecologically more efficient technology. Furthermore, we view leapfrogging not as simply skipping one step of technology development, but as leaping ahead of existing industries and becoming a technological leader [10]. Cutting-edge innovative technologies are, however, typically subject to major uncertainties about their future practical and economic performance. They are thus ruled out in the market in favor of established (and often ecologically less sustainable) technologies that could mobilize economies of scale at an earlier point in time [32, 33]. In order to realize a leapfrogging, a NIC must therefore possess considerable technological and organizational know-how, financial and personal resources, and visionary policy frameworks. The general necessary conditions for a leapfrogging are [9]:

\footnotetext{
${ }^{3}$ In the remainder they will be named "MBR package plants”.
} 
- A minimal endowment with basic infrastructure, as well as technological and organizational absorptive capacity;

- Government interventions in the NIC that strengthen incentives for the uptake of innovative technologies; and

- Technology transfer and financial assistance from developed economies.

Minimal infrastructure is defined as a reliable provision of energy, water and transportation, as well as a stable political and macro-economic environment [9]. The absorptive capacity of NIC actors is of key importance, as in most cases innovative technologies need to be adapted to the specific regional and local contexts of the leapfrogging country [19]. Therefore, as Sauter and Watson [31] state, the success of leapfrogging does not only depend on technological capabilities, "but it needs and in most cases must involve leapfrogging in other areas such as policy [9] or organizational structures [13]. The embeddedness of technology into the socio-institutional context requires leapfrogging in broad terms."

As a consequence, strategic government interventions in the NIC often play a key role. Especially in highly state-regulated infrastructure sectors, the provision of governmental incentives to adopt clean technologies is a crucial precondition for a leapfrogging [10], though uncertainty and high costs often lead to the neglect of these ideas in policy-making [34].

Finally, traditional leapfrogging theories assume that NICs lack financial and technological resources as well as key practical and organizational know-how, thus making technology transfer and foreign assistance of crucial importance. This is especially the case with the importation of know-how through foreign direct investment, licensing or joint ventures [19, 35]. It is therefore sometimes implicitly argued that intensive foreign direct investment in combination with a basic (regulation-induced) demand in the respective NICs are sufficient conditions for initiating a leapfrogging development [36].

This view is increasingly criticized as being too simplistic [9, 37]. Evidence is growing that leapfrogging cannot generally be realized by one isolated actor group but that a dynamic and systemic interplay of different actors (research organizations, international and domestic companies, government agencies, associations) and the respective institutional context is needed. Or, as Perkins [9] notes, "Goal-oriented partnership between various actors in a technology system, both at the national, regional and international level, is a critical unifying element of any leapfrogging strategy."

We thus propose in this article to base leapfrogging on a socio-technical systems perspective which provides such a systemic view on social and technological preconditions for innovation [20]. The "technological innovation system" (TIS) approach [21, 38, 39], in particular, emphasizes the importance of goal-oriented partnership among complementary stakeholders, and recently, has also started to explicitly conceptualize geographical structures. The TIS approach is especially well suited for studying the emergence of new industries. Due to its strong focus on technology development however, a TIS-based perspective runs the risk of not adequately addressing implementation and user-related problems of leapfrogging. For the analysis of transitions in infrastructure sectors, we consider this a minor weakness because implementation is often decided by expert committees and state-led organizations. We will nonetheless revisit this caveat in the concluding section.

\subsection{Technological innovation systems and leapfrogging}

The innovation system literature relies on the assumption that (potentially radical) innovation is the outcome of interaction among complementary actors (e.g. firms, research institutes, government agencies or associations) in complex networks embedded in specific institutional structures [40]. This systemic view of the innovation process was first elaborated 
in the "national innovation systems" concept [41-43], later leading to alternative proposals of "sectoral” [44], "regional” [45] and "technological” [46] innovation systems. In terms of assessing infrastructure sectors, studies have mostly focused on the technology perspective [47-49]. TISs are not delimited by geographic boundaries such as regions or nation-states. They are rather defined as "a set of networks of actors and institutions that jointly interact in a specific technological field and contribute to the generation, diffusion and utilization of variants of a new technology and/or a new product” [21].

An innovation system perspective enables the assessment of future development options, as well as the factors that induce and hinder innovation. Measuring a system's performance, e.g., how well it contributes to the generation, diffusion and utilization of a new technology, has therefore received considerable attention in the past few years [39, 50-52]. Performance can be assessed by relating to a number of core processes or functions [39, 50]. In the following we will mainly follow Bergek et al. [39], which proposes a multi-step analysis of system performance. First, the boundaries of a TIS are defined. Subsequently, the relevant structural elements (actors, networks and institutions) are identified and analyzed. Next, the functional pattern is assessed by a set of eight functions: "knowledge development," "diffusion of knowledge about the innovation," "influence on the direction of the search," "entrepreneurial experimentation," "market formation," “creation of legitimacy," "resource mobilization" and "development of positive externalities." 4 Finally, inducement and blocking mechanisms for the innovation of interest are extracted to enable the formulation of supportive policies.

In a well-performing TIS, complementary actors from research, companies, authorities and intermediary organizations jointly generate and diffuse a new technology and help to shape matching institutional setups and markets. The first two basic conditions for a leapfrogging - absorptive capacity and government intervention-are thus also met. Integrating the third leapfrogging precondition —international technology transfer-into the TIS approach is slightly more complex. Most of the empirical studies on TIS thus far have focused on specific countries or provided comparative analyses of a limited number of national cases [51, 53-55]. This narrow focus is inappropriate for innovation system studies in NICs because they are often strongly export-oriented and interdependent with actors, networks and institutions from a variety of foreign countries [35]. In the following, we thus introduce a spatial differentiation by explicitly positing NIC-bound TIS structures in their international context.

\subsection{National and international segments of TIS and their coupling domains}

The actors, networks and institutions of a TIS may span several countries or even the whole planet [21, 23, 39, 46]. As leapfrogging mostly refers to specific countries, we propose to analytically distinguish three segments of the TIS under investigation. First, actors, networks and institutions that are "located" or primarily active in the NIC belong to a national subsystem of the TIS (or shorter: national TIS). Second, all other actors, networks and institutions that could be identified in the technological field are attributed to the international TIS. ${ }^{5}$ This segment typically comprises globally operating actors, such as transnational companies, but also encompasses small and medium-sized enterprises, research institutes, universities, or intermediary actors involved in technology innovation around the world. Third, actors, networks and institutions from the international TIS segment that substantially influence the national TIS and vice versa will be treated as coupling domains [56].

\footnotetext{
${ }^{4}$ Indicators for assessing performance levels for each function are given in table 2 and 3 in the results section.

${ }^{5}$ It would be more appropriate to call this segment the "general TIS, excluding the specific national TIS structures in focus." As this would be rather awkward, we use the simpler version of "international TIS" (as perceived by the NIC).
} 
In order to formulate a set of ideal-type leapfrogging trajectories, the TIS analysis methodology proposed by Bergek et al. [39] has to be adapted. To this end, we analyze the structure and performance of the national TIS in the NIC of interest so that the maturity of the TIS structure, its functional strengths and weaknesses, and stimuli and obstacles can be identified. The resulting performance assessment can thus be interpreted as the "technological capability" of the NIC-bounded TIS segment. In a second step, we assess the structures and functionalities of the international TIS, emphasizing actors, networks and institutions that could potentially reach into the NIC context (see [22, 23]). In order to generate comparable results, we rely on the same functional indicators as elaborated above (see section 2.2). The third step of analysis addresses the coupling domains between the national and the international segments of the global TIS. In export-oriented NICs (especially China), research institutes, universities, associations, and even politicians are increasingly involved in international networks and projects. This final step of analysis, therefore, focuses on knowledge and technology transfer channels, such as foreign direct investment, technology licensing, joint ventures, migration of experts, international research cooperation, or international conferences. Deficits identified in the national TIS may be compensated by couplings with international TIS structures. As an example, weak "knowledge formation" in a NIC could be compensated by a strong coupling of local universities with foreign universities through joint research projects. Thus, this last step broadens our understanding of the third necessary condition for leapfrogging from existing literature-technology transfer and financial assistance from developed countries - by operationalizing it as the interaction between spatially differentiated subsystems of a TIS.

\section{Ideal-type leapfrogging trajectories}

Based on this scheme of analysis, the relative performance of the national and international TIS segments and their coupling domains can be assessed. By combining all possible permutations of this distinction, eight ideal-type leapfrogging trajectories can be derived, as shown in Table 1.

Table 1: Ideal type leapfrogging trajectories

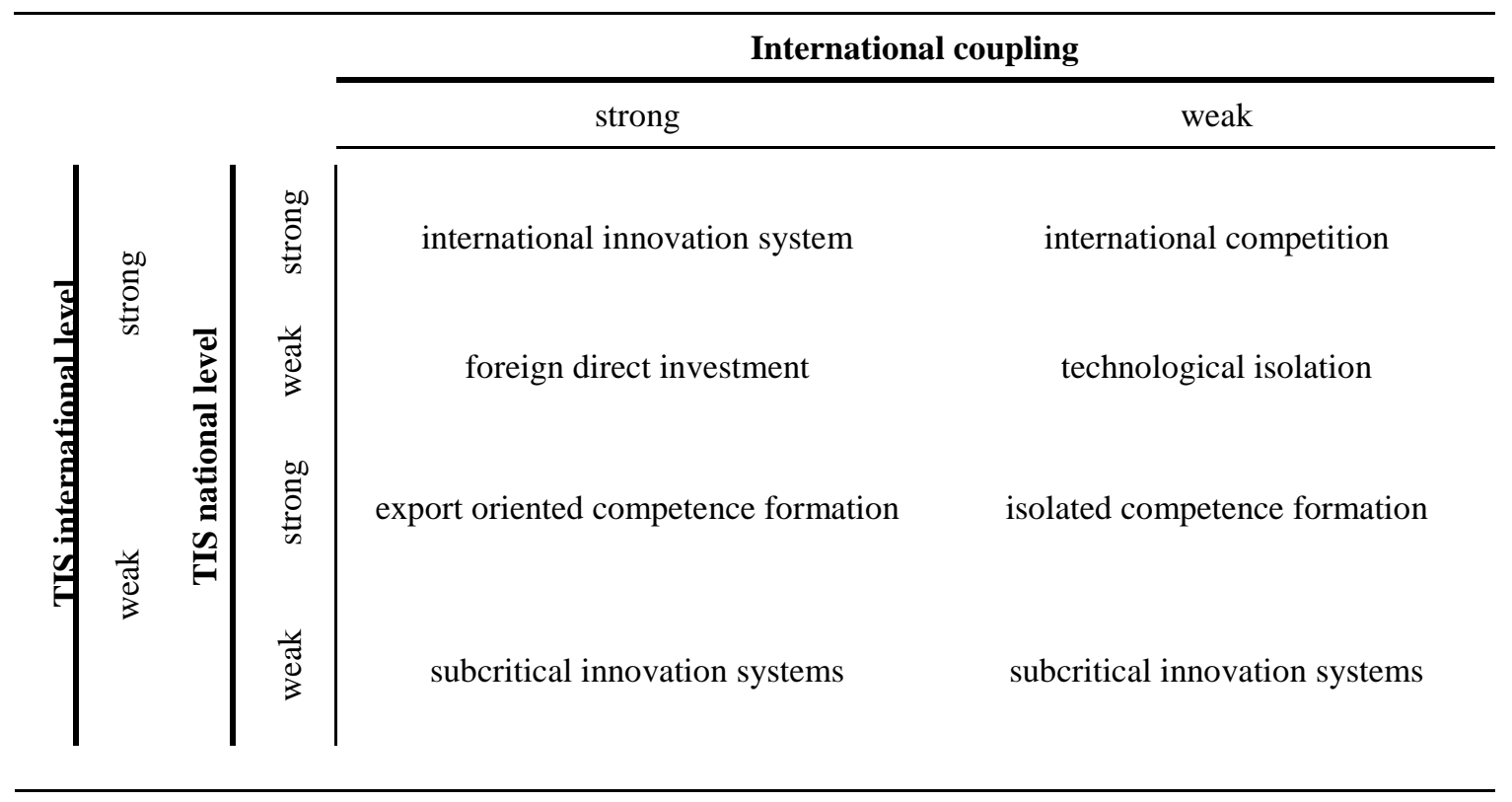


In the following, one of the possible trajectories will be left out and two of them will be merged into one distinct trajectory. The scenario "technological isolation" is not of further interest, as it describes a situation in which innovative activity takes place only in innovation systems at the international level, isolated from the NIC of interest. The "subcritical innovation systems" scenarios both describe situations where leapfrogging is improbable because of a lack of innovative actors, networks and institutions both at the international and national level. We therefore merged them into one single "subcritical innovation system" trajectory. Fig. 1 illustrates the remaining, revised set of six clearly distinct trajectories.

Figure 1: Analytical framework based on ideal-type leapfrogging trajectories

A international innovation system
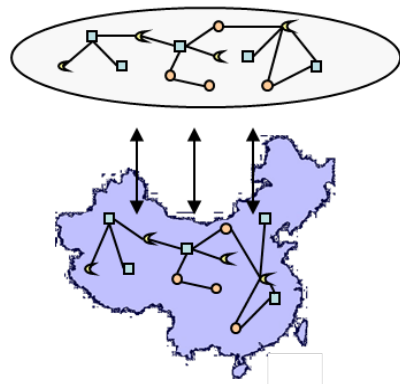

D

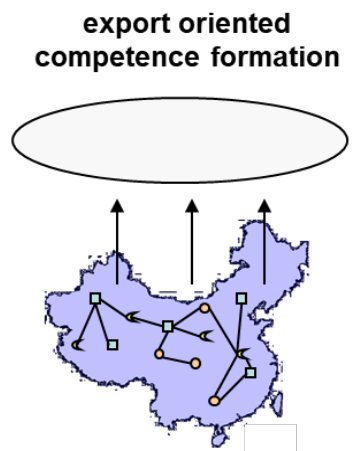

$\longrightarrow$ international level

national level of NIC

Source: Own design
B international competition
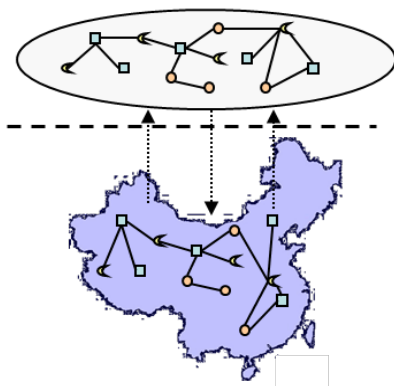

$E$
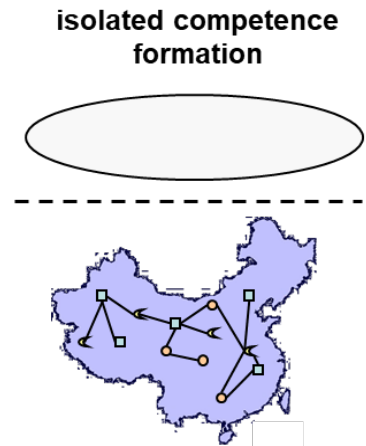

$\square$ company

( institution
C foreign direct investment

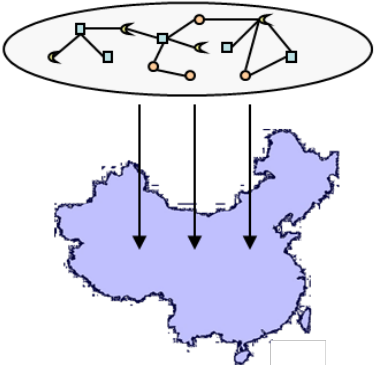

F

subcritical innovation systems
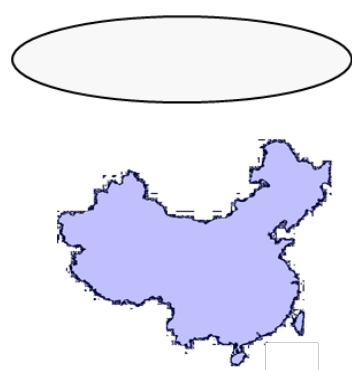

Leapfrogging trajectory C, foreign direct investment, describes the "classic" starting point of most of the scientific literature on leapfrogging [9], in which international actors introduce cutting-edge technologies in a NIC. TNC strategies and incentives provided by the NIC government for attracting cutting-edge technologies are of key importance here. This trajectory has been discussed in various case studies, like the Chinese automobile industry $[10,57]$ or mobile phone telephony in NICs $[16,37]$. Based on our typology, this core trajectory of existing leapfrogging studies can now be complemented with additional trajectories.

The isolated competence formation trajectory (trajectory E) is the contrary to foreign direct investment and the classic case of innovation system studies that apply a strictly national focus. Here, leapfrogging develops inside the NIC in an endogenous bottom-up process, independently from a weakly performing international TIS. New industries or products develop in protected markets within a NIC. This trajectory may be found in 
dependence theory [58] or import substitution literature [59]. Here, leapfrogging depends mainly on the increase of domestic basic knowledge and learning through pilot experiments and protected markets provided by the NIC government.

Trajectories A and B are intermediate forms, in which the different international coupling patterns can lead to two fundamentally different trajectories. The international innovation system trajectory describes a case in which both TIS segments are integrated in a truly international innovation system. The international competition trajectory, in contrast, is a situation in which technological capabilities develop in mutual isolation and strong competition between the national and the international TIS. International knowledge transfer can only be weak or without mutual consent, as in the case of reverse engineering. The preconditions for leapfrogging are very different in these two cases. In the former, leapfrogging can develop on the basis of quick knowledge and technology transfer between different locations as for example in innovation processes in the pharma or automobile sector. In the latter, leapfrogging will occur in strong competition, as in the competitive development of space technology in the United States and the Soviet Union during the Cold War.

Export-oriented competence formation (trajectory D) is another intermediate case. Here, the NIC builds up know-how with the strategic intention of exporting the developed products back to industrialized nations, such as in the development of a specialized information and communication technology industry in Bangalore, India.

The last trajectory (E), subcritical innovation systems, describes a situation in which only weak innovative activities and underdeveloped TIS structures can be identified in both segments. In this case, leapfrogging trajectories could only be initiated by a proactive TIS development policy encouraging experimentation and the creation of TIS structures, such as in the early phase of nano-technology development; a new technology with broad application potential emerged as an idea without any commercial application or localized innovation system structures.

The six trajectories should be understood as ideal-type development options and not as mutually exclusive, deterministic development paths. A NIC can change the trajectory or can combine elements of different trajectories. The main objective of the typology is not to strictly define the future development path of a technology, but to provide a tool for identifying and analyzing leapfrogging trajectories based on a spatially sensitive socio-technical systems perspective.

\section{Methodology}

Innovation system analysis has to deal with high complexity. TIS studies therefore typically rely on a combination of different data sources. The empirical case study was prepared based on an extensive review of secondary data, literature and internet sources. Based on the insights from this preliminary research, an extended interview campaign was conducted with 30 key experts in MBR package plant technology from TNCs, universities, associations and authorities in Europe and China. The interview data were collected in an interview campaign in Beijing, Xi'an and Shanghai, as well as in Switzerland and Germany in winter 2008. Experts were chosen through a three-step "snowballing” [60] process: 1) key experts in the field were identified and eight key experts were interviewed in Switzerland and Germany; 2) an initial interview series with ten Chinese experts from Beijing was planned based on the recommendations from the first interview phase; and 3) a more focused interview series was organized with 12 experts in Beijing, Shanghai and Xi'an. The interviews covered high-ranking experts from Swiss, German, American, Canadian, Japanese, Chinese and French companies, as well as experts from Swiss, German and Chinese universities and from Chinese design institutes, authorities and intermediary organizations. ${ }^{6}$

\footnotetext{
${ }^{6}$ A more detailed summary of the affiliation of interviewed experts is included in the appendix
} 
All interviews, which lasted between 45 minutes and 2 hours, were conducted with a semi-standardized interview guideline that was designed following Bergek et al.'s [39] functional TIS analysis. Two main thematic blocs were covered: 1) the structural properties of the TIS, such as relevant actors, networks and institutions in the field of MBR package plants in China or at the international level; and 2) indicators for the functional analysis of the innovation system both at the international and national level. All interviews were recorded, fully transcribed and analyzed using "qualitative content analysis," following Gläser and Laudel [61], through which information is synthesized in a three step process, including data extraction based on a pre-defined code list, analysis of the extracted information, and modification of the original code list and underlying theories based on the results.

\section{Case study: MBR package plants in the Chinese wastewater sector}

The following section provides an overview of the empirical case study and defines the boundaries of the TIS in focus. In section 5.2. and 5.3, the results of the interview campaign will be presented. First, we will analyze the performance of the Chinese TIS for MBR package plants; subsequently, we characterize the respective international TIS and finally the coupling domains.

\subsection{Defining the TIS in focus}

The core of a TIS is defined by a technology that promises better (environmental) performance. Also the discussion on leapfrogging increasingly relates to potentially more sustainable technologies. However, it is by no means an easy task to clearly define which technologies will be more sustainable options for a given sector. We therefore first conducted a broad investigation of innovative wastewater treatment technologies in Europe. Based on this preliminary research, MBR package plants were chosen as the focal element of the subsequent TIS analysis because they are currently considered a radical and promising alternative to centralized wastewater treatment due to their high suitability for designing small-scale onsite wastewater treatment systems [27, 29, 62, 63].

With MBR package plants, domestic wastewater can be cleaned onsite in a reasonably small tank. In the plant, wastewater is conducted through several small compartments where solid matters settle and aerobic bacteria first perform nutrient removal, and then membrane modules filter the wastewater, thus producing a high hygienic water quality. This "permeate" water can then be reused inside the building as service water for toilets, washing machines or garden greening. ${ }^{7}$ The central element of MBR package plants is a membrane module that eliminates most pathogenic germs and viruses from the effluent [64]. MBR package plants are a radical innovation because their application requires a change in the underlying paradigm of the wastewater sector away from a centralized net-bound utility to a decentralized mass production logic. Existing water utility providers typically have little experience with the application and management of dispersed facilities and usually have no direct contact with private customers [63]. Despite technological challenges, MBR package plants are thus also subject to major organizational and management challenges.

Despite remaining technical problems (high energy consumption, clogging of the membranes, etc.) MBR systems have experienced sustained market diffusion during the last decade [65]. MBR technology is applied in both large-scale, centralized and small-scale municipal systems. Most research and development is focused on large-scale applications, but small-scale MBR package plants use very similar process designs, and therefore directly benefit from advances in large-scale MBR technology. In the following discussion, we thus

\footnotetext{
${ }^{7}$ Usually, such recycling systems can reduce freshwater consumption of residential buildings by approximately $30 \%$. However, from a technological point of view, recycling rates of up to $80 \%$ could be feasible [79].
} 
address both the development of MBR technology as a whole and specifically for MBR package plants. Small-scale MBR package plants are mainly used in hotels, offices, restaurants, ships, remote settlements, as well as for treating highly loaded wastewater from food production or other industries. Industrial applications of MBR package plants are excluded in this study.

The value chain of MBR package plants encompasses component suppliers that provide tanks, pumps, valves, electronic equipment and the membrane module. Often these components are assembled into a MBR package plant by specialized engineering companies. Installation and maintenance of the plants is typically outsourced to plumbers, but at times plant manufacturers also provide comprehensive service and maintenance contracts. MBR package plant manufacturers often buy their membrane modules from specialized membrane manufacturers.

\subsection{The Chinese TIS for MBR package plants}

The structural analysis of the TIS, encompassing actors, networks and institutions relevant to the innovation [39], will be followed by a short discussion of major niches in which MBR package plants are currently applied. Later, the functional performance of the TIS will be assessed, following the functional approach introduced in section 2.2.

\section{Structural analysis}

Development of MBR technology in China started in 1991, but was limited during the 1990s to basic research and a few pilot applications [66]. In 1998, the first commercial MBR plant was installed in Dalian. Only after the year 2000 did research on, and development and application of MBR systems become common practice [67]. By 2006, 254 full-scale MBR systems had been installed in China [67] and annual market growth reached $100 \%$ in the consecutive years [66].

Today, a multitude of actors are involved in basic research on and the development of MBR technology in China. Interviewed experts estimate that 80 Chinese membrane brands are on the market. At least 33 Chinese companies and research institutes are involved in the design and application of MBR systems [67], and 45 Chinese universities, research institutes and government agencies are directly involved in research projects on MBR technology [68]. Even though many actors are pushing MBR technology, only a few of them are explicitly focusing on MBR package plants. The most prestigious practical applications of MBR technology in China have so far been realized in large-scale, centralized municipal or industrial wastewater treatment plants.

Formal innovation networks in the field of MBR package plants could not be identified. Nevertheless, Chinese companies, research institutes and universities often interact in specific pilot plant projects or even in commercial applications of MBR package plants. The central government started subsidizing MBR technology development in 1996, in the ninth five-year $\operatorname{plan}^{8}$ and, since 2002, also in a strategic national technology development plan (Plan 863) [67]. Despite these efforts, all interviewed experts for MBR package plants complained about missing networking structures in the TIS. One manager of a Chinese company said:

“There is no real association or club [supporting onsite wastewater treatment technology]. Just recently there are some conferences where we [supporters of

\footnotetext{
${ }^{8}$ China defines its mid-term policy goals in Five-Year plans which constitute an important source of information about China’s development priorities in politics, society and the economy.
} 
onsite wastewater treatment] could slowly become a small community. But in general too few people are really interested in it and lobbying for it.”

Most interviewees believed that institutional factors originating in the Chinese wastewater sector are of overwhelming importance for the future success of the technology. The sector is strongly regulated and politically managed. Application potentials of MBR package plants are thus strongly influenced by regulative and cognitive institutional contextual factors, such as national and local regulations, or the strong risk aversion of decision-makers. One NGO representative commented:

"If you look at the way that regulations are set and the way the targets are set, efficiency is not a top priority. The way that [...] government officials have their own performance assessed, it's highly risk averse. So the one thing they don't want is to be told that they haven't complied with standards. [...] Their only real concern is to make sure that it [the standard] is met.”

The policy experts interviewed accordingly strongly favor conventional centralized wastewater treatment concepts because they have proven reliability, feasibility and constant performance in Western industrialized countries in the past, and they match Chinese standards.

New regulations, including increasingly demanding wastewater quality standards and building codes, on the other hand, provide growing niches for MBR package plants in China. Cities suffering from water scarcity, like Beijing and Tianjin, have formulated policies asking for onsite wastewater treatment and started implementing ambitious water-recycling projects. For water recycling, MBR systems are often applied because of their reliably high treatment quality. The largest niche is due to a regulation in Beijing that mandates onsite wastewater facilities in new residential buildings exceeding a total construction area of 30,000 $\mathrm{m}^{2}$ [69]. A local manufacturer of MBR package plants and about four local engineering companies are supplying this niche, largely with self-made MBR systems and other onsite wastewater treatment equipment. Our interview partners also identified niches in cities in Central and Southern China, but these are often very small, geographically isolated from each other and served by different actors. Other small niches exist for specific applications, such as car wash systems or wastewater recycling in hotels or prestigious buildings (e.g., for the Olympic Games in Beijing).

\section{Functional analysis}

Analyzing the functional performance of the Chinese TIS reveals major deficits, shown in Table 2. Since the TIS as a whole is still in a formative phase, not all functions are fully developed [39]. The functions "diffusion of knowledge about the innovation," "creation of legitimacy" and "development of positive externalities" show remarkably low performance. As shown before, Chinese experts claim that the central problem for the diffusion of knowledge about the innovation is that advocacy coalitions, such as associations or formal networks, are missing, which could facilitate dissemination of knowledge about MBR package plants to the relevant authorities and regulative organizations. ${ }^{9}$

The interviewees also identified other hindering factors for successful diffusion of knowledge: Design institutes_-very important actors in Chinese infrastructure sectors-have

\footnotetext{
${ }^{9}$ In the transition literature, this lack of coordination has been conceptualized with missing "vertical linkages” [7]. Vertical linkages describe interactions between actors from different levels, such as between local practice (niche) and national level policies (macro).
} 
not yet integrated MBR package plants into their design guidelines. Experts stress that this gap in standardization strongly hinders diffusion. A wastewater technology scientist said:

"The most important step is trying to standardize the technology. For centralized systems we already got all their specifications, the design guidelines for design institutes. But for onsite systems not yet. As long as the guidelines are not clear, the development needs a lot of time.”

Also "creation of legitimacy" shows low performance. As mentioned before, few TIS actors are strongly engaged in the promotion of onsite wastewater treatment systems. Furthermore, an overall suspicious attitude towards the safety and controllability of onsite wastewater treatment plants hinders the creation of legitimacy. Similarly, in the general public, basic knowledge about water problems and the need for radical changes in the wastewater sector is still very low. A professor for wastewater technology points out:

"In China, if we try to popularize such a kind of system [MBR package plants in a residential district], firstly we need people and experts to understand us. Many still do not understand at all the importance of the construction of a new urban water system.”

"Development of positive externalities" is a function that typically forms only in later development stages of a TIS. In the evolving MBR package plant TIS, only a few industry actors and networks sustain the development of the technology. In fact, our interviews did not reveal any sign of positive externalities forming inside the TIS or in closely related TISs. 
Table 2: Functional performance of the Chinese TIS for MBR package plants

\begin{tabular}{|c|c|c|}
\hline TIS functions & Indicators & Performance of the Chinese TIS \\
\hline Knowledge development & $\begin{array}{l}\text { R\&D projects, no. of involved actors, } \\
\text { no. of workshops and conferences, } \\
\text { network size and intensity, no. of niches }\end{array}$ & $\begin{array}{l}\text { Medium to high performance: } \\
\text { Many commercial actors and research initiatives, but only } \\
\text { few niche applications }\end{array}$ \\
\hline $\begin{array}{l}\text { Diffusion of knowledge } \\
\text { about the innovation }\end{array}$ & $\begin{array}{l}\text { activities of industry associations, } \\
\text { websites, conferences, linkages among } \\
\text { key stakeholders }\end{array}$ & $\begin{array}{l}\text { Low performance: } \\
\text { Development in isolated niches, few horizontal and vertical } \\
\text { linkages among key actors, weak networking structures }\end{array}$ \\
\hline $\begin{array}{l}\text { Influence on the direction of } \\
\text { the search }\end{array}$ & $\begin{array}{l}\text { Targets set by the government, no. of } \\
\text { press articles that raise expectations, } \\
\text { visions and beliefs in growth potential }\end{array}$ & $\begin{array}{l}\text { Low to medium performance: } \\
\text { Targets set by government could support the innovation, } \\
\text { but few public discourses in the press, skepticism about } \\
\text { future growth potential }\end{array}$ \\
\hline $\begin{array}{l}\text { Entrepreneurial } \\
\text { experimentation }\end{array}$ & $\begin{array}{l}\text { No. of new entrants, no. of } \\
\text { diversification activities of incumbents, } \\
\text { no. of experiments }\end{array}$ & $\begin{array}{l}\text { Low to medium performance: } \\
\text { Few new entrants, many incumbents with diversification } \\
\text { strategies, few but highly innovative experiments }\end{array}$ \\
\hline Market formation & $\begin{array}{l}\text { No. of niche markets, specific tax } \\
\text { regimes and regulations, environmental } \\
\text { standards }\end{array}$ & $\begin{array}{l}\text { Medium to high performance: } \\
\text { Creation of several niche markets by political regulations } \\
\text { in water scarce cities, generally rising environmental } \\
\text { standards and wastewater fees }\end{array}$ \\
\hline Creation of legitimacy & $\begin{array}{l}\text { Rise and growth of interest groups and } \\
\text { their lobbying activities }\end{array}$ & $\begin{array}{l}\text { Low performance: } \\
\text { No interest groups and lobbying activities identifiable, no } \\
\text { standardization of decentralized MBR wastewater } \\
\text { treatment plants }\end{array}$ \\
\hline Resource mobilization & $\begin{array}{l}\text { Availability of competence/human } \\
\text { capital, financial capital, complementary } \\
\text { assets for key actors }\end{array}$ & $\begin{array}{l}\text { Medium performance: } \\
\text { Abundance of highly skilled human capital, core actors get } \\
\text { access to financial resources, complementary assets not yet } \\
\text { mobilized }\end{array}$ \\
\hline $\begin{array}{l}\text { Development of positive } \\
\text { externalities }\end{array}$ & $\begin{array}{l}\text { Emergence of pooled labor markets, } \\
\text { intermediate goods and service provi- } \\
\text { ders, information flows and knowledge } \\
\text { spill-overs }\end{array}$ & $\begin{array}{l}\text { Low performance: } \\
\text { In the current, formative stage of the Chinese TIS for MBR } \\
\text { package plants, positive externalities have not yet } \\
\text { developed. }\end{array}$ \\
\hline
\end{tabular}

Functions and indicators based on Bergek et al. [39] and Markard and Truffer [21].

Some TIS functions show better performance. "Knowledge development,” mainly realized by the plentiful research institutes and universities, seems to be well established. China has experienced an unprecedented boom in scientific publications on MBR technology since 2000 and recently became the global leader in MBR-related publications [68, 70]. It is developing scientific knowledge quickly, both in well-funded national science programs as well as in international networks [68]. Academic and company interviewees stress that in the Chinese TIS, universities and research institutes are not only engaged in basic research but also directly involved in the practical application of the technology. The former president of a Chinese industry association said:

"In China, technology innovation comes from the universities and research institutes. [...] More and more are involved in it. And some institutes transferred into companies. [...] So in China normally at this stage, universities and institutes are the backbones for the research and development of water pollution prevention technology.” 
Nevertheless, in knowledge development as well, most activity is so far focused on scientific research and application of MBR technology in large-scale wastewater treatment plants.

"Market formation" is another relatively well-performing function in the Chinese TIS. All interviewees believe that future market prospects for MBR plants are very high. The current growth rate of up to $100 \%$ is widely expected to continue for the next five to ten years [66, 67]. The interviewees also claim that market formation is mainly dependent on regulative institutions, such as water fees and building codes or design standards. Water fees show an increasing in the last few years, which improves the market prospects for water recycling systems. The chief engineer of a TNC stated:

"We think in China water tariffs will increase very quickly. [...] And the higher the freshwater price, the more advantages water reuse has."

However, markets form in a geographically dispersed way: water fees vary substantially from city to city [71], which means that markets for MBR package plants are so far mainly created in specific water-scarce cities in North and Northwest China.

"Entrepreneurial experimentation" shows low to medium performance. Few companies are focusing on building MBR package plants and only one (Beijing Origin Water) is supplying them in large numbers. Experts claim that these companies are on average too small to develop their own innovative solutions. A Chinese innovation scientist said:

"At this stage, in this market there are only small and medium enterprises. It is quite difficult for them to survive in the market. So they usually do not have enough funding, money and enough talent to do research and development of their own technology."

Finally, "Influence on the direction of the search" and "resource mobilization" still show low to medium performance. Analysis of our interviews reveals a strong lack of discourses about the advantages of MBR package plants. Accordingly, visions about the innovation that could direct the search and legitimize the TIS are restricted to isolated entrepreneurs and pioneers. This missing legitimization could in turn hinder resource mobilization for MBR package plants. At the moment, interviewees only name local governments as a source of investment. The vice-director of a Chinese company noted:

"Our systems are a little bit expensive, but that's no problem, the finance comes from the government. [...] In China, now the government supports the infrastructure construction. So the first investment into onsite systems often comes from the local government."

At the same time, the central government implemented considerable investment programs in the wastewater sector in the $11^{\text {th }}$ and $12^{\text {th }}$ five-year plans and in an economic stimulus package in 2008. In the $11^{\text {th }}$ five-year plan, about 34 billion US $\$$ were invested into wastewater infrastructure [71] and the current plan seeks to invest another 50 billion US\$ (interviewee from a consulting company). Even though a lot of investment is planned for sewer construction and sludge treatment, some money also trickles down to MBR package plant manufacturers. Company interviewees are thus not currently complaining about a shortage of resources.

In sum, the analysis of the Chinese TIS exemplifies a TIS in an emerging phase, with many of its functions showing low to medium performance. Still, intensive knowledge development, rising water prices and the optimistic evaluation of Chinese experts about future 
market prospects of MBR technology are likely to sustain the development of the Chinese TIS in the foreseeable future. In addition, this tendency will likely be supported by a continuing rapid urbanization, increasing water scarcity and strong pressure from water pollution.

\subsection{The international TIS for MBR package plants}

\section{Structural analysis}

At the international level, research and development on MBR technology started much earlier than in China. The first patent had already been issued in 1966 by an American company, but interest in the idea remained low in the USA [72]. Until the 1980s, activity in the field was limited to pioneering lab-scale research in the UK, France, Japan and South Korea [72]. Only between 1980 and 1995 did major breakthroughs occur, and the first commercial applications entered municipal wastewater treatment markets [67]. After 2000, research and commercial applications surged, with an average global market growth of $10.9 \%$ [65]. By the year 2006, about 2,200 MBR systems had been installed worldwide, of which about 258 were located in North America [72] and about $409^{10}$ in Europe [65].

Major actors and centers of scientific research and commercial development are spread around the world: in the United States, Canada, Germany, France, the United Kingdom, Italy, the Netherlands, China, South Korea, Japan, and, to a lesser extent, in Singapore and Australia [68]. The field is currently booming, which is reflected in high actual and expected market growth rates ( $>10 \%$ over the next five to ten years [65]) and exponential growth in scientific publications $[65,68]$.

Some TNCs, such as General Electric, Kubota, Siemens, or Mitsubishi Rayon, are key players in the commercial development and dissemination of MBR technology. General Electric and Kubota in particular form a duopoly in the European and North American markets [65]. However, their dominant position is increasingly challenged by successful new entrants both in Europe [73] and Asia [66]. Most of these TNCs also manufacture and sell medium- to large-scale MBR package plants. However, onsite municipal applications still play a minor role in their overall product strategies. The chief engineer of a TNC stated:
"Yes, I think onsite wastewater treatment has a future, but our company is not much involved in it. [...] Because we have enough work to do for the big plants today. So we will think about that later. [...] Chinese engineering companies are doing these small things."

Some of the interviewees from TNCs even fear that a trend towards smaller wastewater treatment systems could destroy their core business, which is rooted in large civil engineering projects. TNCs are therefore not strongly pushing MBR package plants.

Innovative ideas for MBR package plant solutions are mostly generated in specialized small and medium-sized companies. Especially in Japan, the USA and Europe, several small or medium-sized enterprises exclusively focus on manufacturing and retailing MBR package plants. These companies are active at a national or regional level and sometimes also at an international level [74]. They are dedicated to niche applications of MBR package plants in rural areas, ships, office buildings and hotels. In Germany, for example, about ten competing MBR package plant manufacturers compete in a market of totally about 1 million onsite wastewater treatment plants [75].

MBR technology emerged differently in networks in North America, Europe and Asia. North America invented the first example, but later remained locked in to a specific

\footnotetext{
${ }^{10} 409$ plants were installed had been installed until 2005. In 2008 more than 800 plants had been installed in Europe [73]. These numbers, however, exclude MBR package plants with a capacity smaller than 500 person equivalents.
} 
technological setup (side-stream MBR) and showed fewer activities than other regions of the world [72]. European actors entered the field later, developed the technology first in industrial applications and extended the activities greatly after 2000, especially in research networks supported by research programs of the European Union after 2006 [65]. In Asia, pioneering research and application was mostly restricted to Japan and South Korea, where the development focused on municipal and small-scale application. After 2000, activities surged also in this part of the world, and Japanese TNCs like Kubota gained considerable market shares globally. At the same time, China emerged as a new center of R\&D and commercial application [67, 72].

Fig. 2 illustrates the geographic structure of the international TIS, which can be divided into three partly isolated networks of technology development. Even though TNCs are also supplying MBR package plants, they are depicted outside of these core TIS networks because they mainly focus on centralized wastewater systems. However, Fig. 2 also illustrates that these TNCs are active in all three networks, and could therefore be in a key position to facilitate knowledge transfer between them.

Figure 2: Global distribution of commercial and scientific actors in MBR technology development.

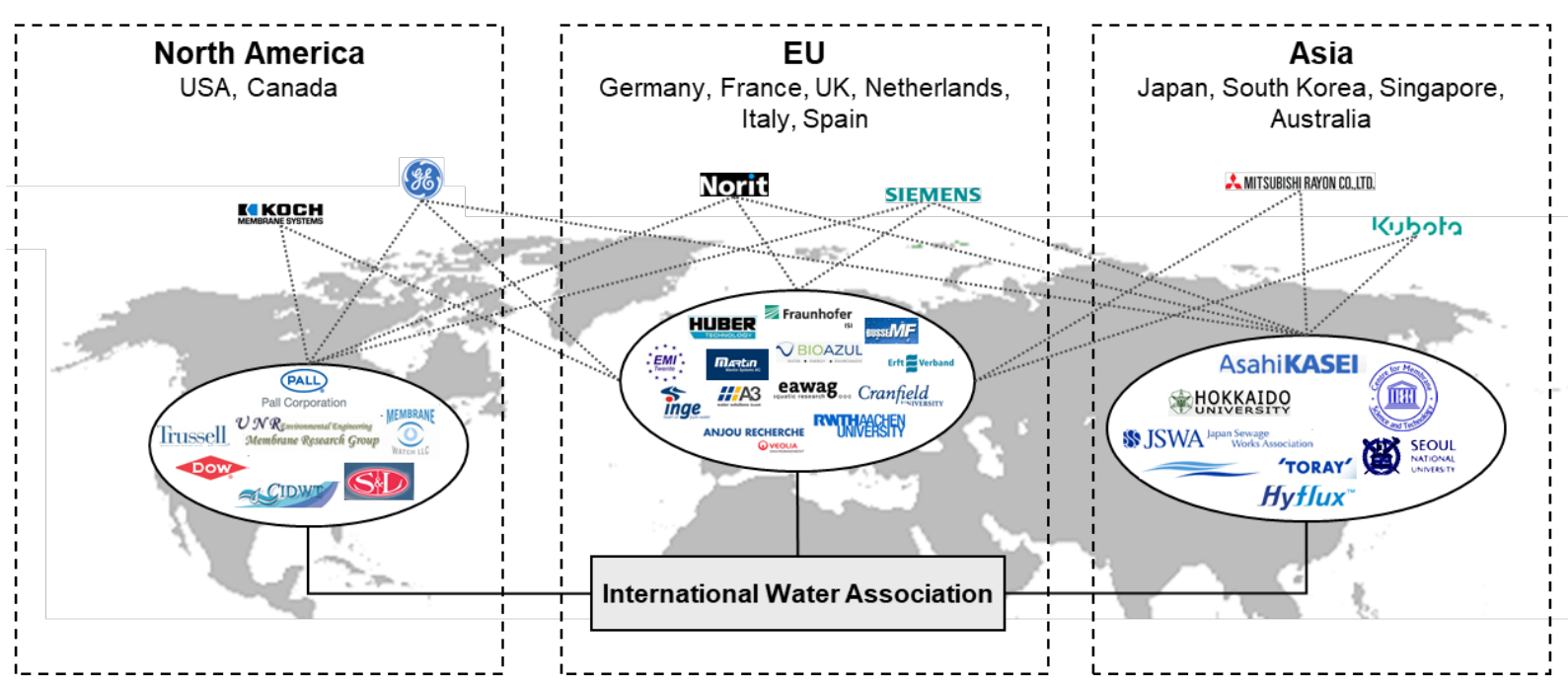

The three networks are also strongly connected. Regular interaction of major players is observable at international conferences, trade fairs, in networking agencies, industry associations, and especially at events of the international water association (IWA). However, our interviewees stressed that MBR package plants still occupy a marginal position on the agendas of these international events.

Relevant institutions vary greatly between different regions of the international TIS. The European Union, for example, provides a particular institutional setting. A technology cluster was founded in the sixth framework program, ${ }^{11}$ promoting the development of MBR technology in four distinct projects, gathering 50 companies and institutes from Europe and around the world [65]. At the same time, regulative institutions and standards of the European Union strongly affect the MBR package plant TIS.

Lastly, niches for MBR package plants developed in countries that historically have a relatively large amount of onsite wastewater treatment plants such as the USA, South Korea, Japan or Germany, but also in water-scarce regions in North Africa, the Arabian Peninsula

\footnotetext{
11 The "Framework Programs for Research \& Technological Development" allocate the financial funds of the European Union for research promotion. In the realm of the 6th framework program (2006-2009), 16 Mio. Euros were invested into four supported MBR projects: AMADEUS, EUROMBRA, MBR-TRAIN and PURATREAT.
} 
and around the Mediterranean Sea [75]. In sum, the structure of the international TIS of MBR technology is rapidly evolving, with many new entrants, established TNCs and research institutes, as well as some relatively quickly growing associations and international conferences. However, like in China, few actors are explicitly focusing on MBR package plant development so far.

\section{Functional analysis}

As shown in Table 3, the functional pattern of the international TIS differs in several ways from the Chinese segment. The interviews reveal slightly more activity at the international level in functions such as knowledge development, entrepreneurial experimentation, or creation of legitimacy.

Knowledge development is mainly happening in well-funded international research projects and in many smaller research initiatives. Company interviewees claim that, in contrast to China, the practical application of MBR package plants and variation in plant design and manufacturing companies is strong in the European Union, Japan and the USA.

Table 3: Functional performance of the international TIS for MBR package plants

\begin{tabular}{|c|c|c|}
\hline TIS functions & Indicators & Performance of the international TIS \\
\hline $\begin{array}{l}\text { Knowledge } \\
\text { development }\end{array}$ & $\begin{array}{l}\text { International R\&D projects, no. } \\
\text { of involved actors, no. of } \\
\text { international workshops and } \\
\text { conferences, network size and } \\
\text { intensity }\end{array}$ & $\begin{array}{l}\text { Medium to high performance: } \\
\text { Plentiful local research projects and small and medium companies } \\
\text { in MBR package plant development, but rather weak presence of } \\
\text { such projects and actors at international networks, workshops and } \\
\text { conferences }\end{array}$ \\
\hline $\begin{array}{l}\text { Diffusion of knowledge } \\
\text { about the innovation }\end{array}$ & $\begin{array}{l}\text { Activities of int. industry } \\
\text { associations, websites, int. } \\
\text { conferences, articles in } \\
\text { international journals }\end{array}$ & $\begin{array}{l}\text { Low performance: } \\
\text { MBR package plants did only recently emerge as a topic in most } \\
\text { journals/conferences/industry associations, no specific industry } \\
\text { association existing for MBR package plants }\end{array}$ \\
\hline $\begin{array}{l}\text { Entrepreneurial } \\
\text { experimentation }\end{array}$ & $\begin{array}{l}\text { No. of new entrants, no. of } \\
\text { diversification activities of } \\
\text { incumbents, no. of experiments }\end{array}$ & $\begin{array}{l}\text { Medium to high performance } \\
\text { Successful new entrants, experiments and pilot tests with MBR } \\
\text { package plants in the European Union, Japan and the USA that raise } \\
\text { expectations, raising interest of incumbents in Japan }\end{array}$ \\
\hline Market formation & $\begin{array}{l}\text { No. of niche markets, specific } \\
\text { tax regimes and regulations, } \\
\text { environmental standards }\end{array}$ & $\begin{array}{l}\text { Low performance (but high future potential): } \\
\text { Potentially big niche markets are evolving in rural areas in the USA, } \\
\text { Germany, France, Korea and Japan, increasingly demanding } \\
\text { regulations for effluent water quality in the USA, European Union } \\
\text { and Japan }\end{array}$ \\
\hline Resource mobilization & $\begin{array}{l}\text { Availability of competence/ } \\
\text { human capital, financial capital, } \\
\text { complementary assets for key } \\
\text { actors }\end{array}$ & $\begin{array}{l}\text { Low performance: } \\
\text { Low interest of private investors for MBR package plant providers, } \\
\text { few complementary assets, no subsidies }\end{array}$ \\
\hline
\end{tabular}




\begin{tabular}{lll}
$\begin{array}{l}\text { Development of } \\
\text { positive externalities }\end{array}$ & $\begin{array}{l}\text { Emergence of pooled labor } \\
\text { markets, intermediate goods and } \\
\text { service providers, information } \\
\text { flows and knowledge spill-overs }\end{array}$ & $\begin{array}{l}\text { Low performance: } \\
\text { Few positive externalities are restricted to isolated niche markets in } \\
\end{array}$ \\
\hline
\end{tabular}

Functions and indicators based on Bergek et al. [39] and Markard and Truffer [21].

Knowledge development in the international TIS is also based on experimentation and commercial experiences with MBR package plants in different application contexts. This is further related to intensive entrepreneurial experimentation in the international TIS. Many small and medium-sized companies entered the field in the last decade, and in the case of Japan, even large companies like Kubota or Mitsubishi Rayon are now active in MBR package plant manufacturing. For example, German interviewees claimed that in Germany entrepreneurial experimentation and competition are very strong, which will probably lead to shake-outs and a consolidation in the industry. The manager of a German company stated:

"Companies are fighting in the German market for onsite wastewater treatment. There really is some house-to-house fighting. Not every company will survive this in the long run."

MBR package pants are mostly niche applications. However, the creation of legitimacy is improving, thanks to support coalitions in some countries. Japan has a long tradition of onsite wastewater treatment ("Jokaso") systems and correspondingly strong legitimization for MBR package plants. Furthermore, in the USA and Germany, associations emerged that are actively lobbying for the interests of onsite wastewater treatment technology. However, interviewees complained that these associations often remain engaged in the promotion of older or less efficient technologies than MBR package plants.

Market formation in the international TIS is still limited, but appears to have great future potential. Some regions could quickly develop into bridging or even mass markets for MBR package plants. Both Japan and the USA already have very large markets for onsite wastewater treatment, and our interviewees stress that also Germany, France and countries in Eastern and Southern Europe provide interesting market potentials. Company interviewees claim that new markets for MBR package plants might emerge in these countries due to increased water scarcity, rising wastewater standards and the ensuing pressure from demographic changes. The CEO of a German company said:

"The market potential in Europe is so large; we limit ourselves to this market. [...] But the development outside Europe is very huge as well.”

Similarly, the manager of a European association noted:

"Rising demand from the USA and Asia affects us in Europe. For example in the USA we estimate that 20 million new systems [on-site wastewater treatment systems, not specifically MBR package plants] will have to be built in the next few years."

Major functional deficits appear in the diffusion of knowledge about the innovation, influence on the direction of the search, resource mobilization and the development of positive externalities. Our interviews reveal that these functions all depend to some extent on the scarcity of networks and the relative weakness of the networks and lobbying groups that do exist. Within the international TIS, lobbying groups for MBR package plants are not yet 
established, and TNCs are not very active in this realm (with the exception of Japan).

Consequently, most networking activities are observable only in isolated national or even

regional contexts. These missing formalized international networks appear, in turn, to hinder the diffusion of knowledge about the innovation, and thus also to restrict the mobilization of financial resources from private investors.

Summing up, in the international TIS, MBR technology is developing dynamically and has a promising actor base and market outlook. However, the most innovative actors are small and medium-sized companies which act in innovative networks in national or even regional contexts, and these are embedded in three distinct geographic networks in North America, Europe and Asia. This fragmented structure of technology development has so far strongly hindered the effective buildup of core functions of the TIS at an international scale.

\subsection{International coupling pattern}

Table 4 reveals that the coupling intensity varies between different functions. Knowledge development in China is strongly coupled to the international TIS. All of the Chinese scientists interviewed have participated in international projects, and Chinese universities are well established in international research networks [70]. The Chinese science system thus efficiently couples international and domestic actors, and thereby improves "knowledge development" in the Chinese TIS. This observation is in line with other studies that focused on international knowledge transfer in the Chinese national innovation system [76, 77]. Influence on the direction of the search also shows a strong, but in this case unfavorable coupling pattern for the Chinese TIS. As shown before, powerful TNCs are active in China, but primarily promoting centralized wastewater treatment technologies. Consequently, their activities have so far led to the importation of centralized wastewater treatment systems, which has hindered influence on the direction of the search and delegitimized the Chinese MBR package plant TIS. Interestingly, experts claimed that activities of the World Bank and the Asian development bank could have had a similar effect. The manager of an NGO stated:

"The big banks, development banks, only give credits for large-scale projects. Starting from 80,000 person equivalents. But surely not for small package plants.”

The most innovative small and medium-sized MBR package plant manufacturers from the international TIS are, in turn, not yet serving the Chinese market. Interviewees from these companies repeatedly stressed that they fear violation of their intellectual property rights and copyright infringement under the current Chinese legislation. 
Table 4: Functional performance and coupling pattern of the international and Chinese TIS for MBR package plants

\begin{tabular}{|c|c|c|c|}
\hline TIS functions & TIS CN & TIS int. & Coupling pattern \\
\hline Knowledge development & + & + & $\begin{array}{l}\text { Coupling of both levels established by universities and research institutes } \\
\text { with intensive exchange in international research projects. }\end{array}$ \\
\hline $\begin{array}{l}\text { Diffusion of knowledge } \\
\text { about the innovation }\end{array}$ & -- & -- & $\begin{array}{l}\text { Weak exchange about successful experiments with MBR package plants. } \\
\text { Only occasional interaction at international conferences. }\end{array}$ \\
\hline $\begin{array}{l}\text { Influence on the direction of } \\
\text { the search }\end{array}$ & - & -- & $\begin{array}{l}\text { Reverse coupling: TNCs and international organizations are essentially } \\
\text { promoting the development of centralized wastewater treatment in China }\end{array}$ \\
\hline $\begin{array}{l}\text { Entrepreneurial } \\
\text { experimentation }\end{array}$ & - & + & $\begin{array}{l}\text { Coupling existing only through market-based transactions. Few } \\
\text { international MBR package plant manufacturers have built up } \\
\text { subsidiaries/joint ventures in China or are selling technology licenses }\end{array}$ \\
\hline Market formation & + & $-/+$ & $\begin{array}{l}\text { Reciprocal coupling: Fast market formation in China is only slowly } \\
\text { supplied by international and domestic MBR package plant products. } \\
\text { Chinese MBR package plant companies are expanding to international } \\
\text { markets. }\end{array}$ \\
\hline Creation of legitimacy & -- & 0 & $\begin{array}{l}\text { No coupling identifiable. Low awareness of Chinese decision makers } \\
\text { about potential benefits of decentralized MBR package plants. }\end{array}$ \\
\hline Resource mobilization & 0 & - & $\begin{array}{l}\text { Weak coupling. Most resources in bot TIS segments are dedicated to } \\
\text { build-up or maintenance of centralized wastewater infrastructure }\end{array}$ \\
\hline $\begin{array}{l}\text { Development of positive } \\
\text { externalities }\end{array}$ & -- & -- & $\begin{array}{l}\text { So far no coupling, but future positive externalities from niche markets in } \\
\text { Germany, Japan, USA might swap over to China through different TIS } \\
\text { actors, many diverse coupling channels possible }\end{array}$ \\
\hline
\end{tabular}

-- Low performance; - Low to medium performance; 0 medium performance; + medium to high performance; ++ high performance; -/+ Low performance but high future potential; $\mathrm{CN}=\mathrm{China}$; int.=international

Table 4 also shows a partly complementary functional pattern of the international and Chinese TIS. Entrepreneurial experimentation, market formation and creation of legitimacy differ considerably between the two segments, whereas the other functions show similar performance. Entrepreneurial experimentation and creation of legitimacy are performing better in the international TIS, but relevant actors are not coupled to the Chinese TIS. Attracting entrepreneurs from overseas and from regions of the TIS where MBR package plants are better legitimized could thus help to improve the functionality of the Chinese TIS. Market formation, in turn, is performing better in China, which could mean that experiences from the large Chinese markets could thereby improve the functionality of the international TIS through exports from Chinese MBR package plant manufacturers.

Finally, diffusion of knowledge about the innovation, resource mobilization and development of positive externalities all show low performance in both segments. Intensifying couplings to the international TIS would thus at the moment very likely not significantly improve these functions in the Chinese TIS segment.

Apart from function-specific coupling patterns, the interviewees identified other relevant coupling channels which could have an influence on different functions simultaneously. They emphasized the importance of knowledge transfer through market interaction, international consulting, migration of highly-qualified professionals, meetings at international conferences and cooperation in international research projects. Travelling experts, in particular, were repeatedly mentioned in the interviews as a decisive coupling channel. A Chinese scientist said: 
"In many Chinese private companies the people have overseas experience. [...] International cooperation, projects and communication is carried out by those people. [...] That's very important especially for new technologies.”

Summarizing, the international TIS segment influences the functional performance of the Chinese TIS mainly in the functions of knowledge development and influence on the direction of the search. Interestingly, the coupling through TNCs seems not to be beneficial for the diffusion of MBR package plants in China.

\section{Discussion}

Based on the results presented and with reference to the six ideal-type leapfrogging trajectories that were defined in section 3, trajectories D, E and F-export-oriented competence formation, isolated competence formation and subcritical innovation systemsare not plausible future leapfrogging trajectories for China's urban wastewater sector. These trajectories assume that only little innovative activity is observable in the respective technological field on an international scale. As we have shown, this is clearly not the case in MBR technology development. Since an emerging TIS for MBR package plants could be identified in China, we can also exclude (to some extent) scenario C, foreign direct investment. The interaction pattern between the Chinese and international TIS can be characterized as a combination of supportive, hindering and missing couplings. Thus, in the current situation, two trajectories, "international competition" and "international innovation system," could be conceivable leapfrogging trajectories in the Chinese wastewater sector.

The first of these trajectories could result from an increasing integration of China into the international MBR TIS. In this scenario, Chinese actors could develop mass manufacturing and implementation of MBR package plants in close cooperation with experts and companies from the international TIS. The strong international coupling in the respective science systems might support such a trajectory. However, more intensive interaction in other functions, such as market formation, entrepreneurial experimentation or creation of legitimacy, might also be highly important. Such an "international innovation system" leapfrogging trajectory is currently limited by the structural and functional deficits in the international TIS, however. Resource mobilization, development of positive externalities and diffusion of knowledge about the innovation are weakly developed in the international TIS. A stronger integration with international actors would thus not necessarily generate additional benefits. Sustaining an international innovation system trajectory will ultimately depend on a more proactive Chinese innovation policy. One of the most critical aspects is the protection of intellectual property rights. As shown before, the propensity of innovative companies from the international TIS to cooperate or to introduce their products to the Chinese market remains low, and will continue to do so as long as their technological know-how is not properly protected. Other policy measures might include the establishment and support of international innovation networks, associations for the application of MBR package plants and measures that improve couplings to international actors, thereby providing entrepreneurial experimentation and creation of legitimacy.

The second conceivable leapfrogging trajectory builds on a diffusion of MBR package plants in the Chinese wastewater sector largely decoupled from the international context. As urban water problems are likely to increase on a global scale in the coming decades, MBR package plant production could become a very promising future industry sector. Implementing the technologies in the Chinese wastewater sector would provide a sizable home market for testing the new concepts and creating legitimacy for later exports. Experiences from the promotion of wind energy in Denmark or photovoltaics in Germany 
show that an explicit industrial policy would be a precondition for this trajectory. A further precondition would be that onsite wastewater concepts be endorsed as an equitable alternative to conventional wastewater treatment in combination with environmentally demanding building codes and design standards (like those that are already applied in Beijing). This would generate the necessary legitimacy for the maturation of an autonomous Chinese TIS. Decision-makers' awareness about the environmental and industrial potential of onsite wastewater technology would have to rise significantly, however. The current structural and functional pattern of the Chinese TIS still shows a lack of advocacy coalitions that actively work on legitimacy creation through lobbying activities, reliable demonstration projects, or network creation.

Our results show that sustaining a leapfrogging trajectory in an NIC is a far more multidimensional task than is assumed in existing leapfrogging literature. Policy options vary widely depending on the specific constellation of innovation capacities in the country as well as internationally. Sustaining an international competition trajectory demands domestic environmental and industrial policies, whereas the international innovation system trajectory would require a strong emphasis on general innovation policy. Sustaining leapfrogging towards sustainable sector structures is thus not confined to environmental policy, but also contains implications for industrial and innovation policy, perhaps augmented by explicit support policies for specific functions of the emerging innovation systems.

\section{Conclusions}

This paper's main objective was to introduce a space-sensitive version of the technological innovation system approach as a conceptual basis to leapfrogging analysis. Based on this concept, an analytical framework was developed and applied to the identification of potentially feasible leapfrogging trajectories in the Chinese wastewater sector. The illustrative case study showed that this approach can generate new insights about future leapfrogging trajectories. Instead of explaining leapfrogging potentials with three generic indicators, as prevalent in existing leapfrogging studies (see section 2.1), the proposed framework allows for much broader identification of preconditions for success and can provide multifaceted policy recommendations.

Even though we limited our analysis to the wastewater sector, we believe that the framework could also be applied to similar network-based infrastructure sectors, such as electricity or transportation. More caution is appropriate when applying it to less statecontrolled and more market-driven sectors, such as computer components or car manufacturing. Here, articulation of demand for the innovation or the societal embedding necessary to accommodate new technologies will be more important. As stated earlier, focusing on the supply side of an innovation may be a permissible simplification in infrastructure sectors, where demand for innovation is mainly generated by government organizations. It is probably fair to assume that policymakers would not generate demand for an innovation that has not developed any supporting systemic TIS structure. Nevertheless, it would still be important to analyze how new technologies are assessed in actual decisionmaking and planning processes of local water utilities, both in NICs and worldwide. Only when the development of new technologies is combined with (often policy-driven) implementation opportunities, may leapfrogging in infrastructure sectors actually take place.

On a conceptual level, further refinements of our framework and the respective methodology are mainly needed in two fields. First, the conceptualization of the international TIS needs better characterization. We had to limit the analysis of the international TIS to a generic and explorative identification of structural components and functional performance. A geographically multi-layered structural and functional analysis of the TIS in its global dimension is needed in future research. The conceptual and methodological challenges of this 
endeavor will be elaborated in a forthcoming publication [68]. Second, a more sophisticated analytical framework must be developed for assessing the international coupling pattern, as well as for assessing the influence of international actors on innovation systems in NICs. Our distinction of innovation systems at the national and international level is only a first and very basic conceptualization of space. Clearly, a more sophisticated multi-scalar and relational understanding of space would be a much more favorable approach [25, 78].

Tackling global environmental change increasingly depends on the technological trajectories followed in NICs. Strong path-dependencies and lock-ins will result, particularly in infrastructure sectors, if opportunities for implementing more sustainable system alternatives are dismissed. Research on sustainability transitions should therefore consider leapfrogging in NICs as a new potential research topic. Conceptual work has to understand transitions as embedded into increasingly complex spatial innovation processes in a globalizing world. The analytical framework developed in this paper represents a first step towards a more geographically explicit understanding of sustainability transitions, but much more work is needed in the future in this field.

\section{Acknowledgments}

The authors would like to thank the Sino-Swiss Science and Technology Cooperation (SSSTC) for the funding of this project. We would also like to thank our project partners from the Chinese Academy of Sciences (project number GJHZ0910) for very helpful feedback. Part of the work was conducted while one of the authors (B. Truffer) was a Fellow in the Sustainability Science Program at Harvard University. This paper also profited from much constructive input at the DRUID conference 2009, the KSI international conference 2009 and a DIME workshop 2009. We would especially like to thank Lars Coenen and Jochen Markard for inputs on earlier drafts and the three anonymous reviewers for very detailed and extremely helpful comments. Last but not least, we thank Eva Lieberherr for proofreading this article.

\section{References}

[1] G.C. Unruh, J. Carrillo-Hermosilla, Globalizing carbon lock-in, Energy Policy 34(10) (2006) 11851197.

[2] A. Rip, R. Kemp, Technological Change, in: S. Rayner, E.L. Malone (Eds.), Human choice and climate change—Resources and technology, Battelle Press, Columbus, 1998.

[3] F. Berkhout, D. Angel, A. Wieczorek, Sustainability transitions in developing Asia: are alternative development pathways likely? Technological Forecasting \& Social Change 76(2) (2009) 215217.

[4] F. Berkhout, D. Angel, A. Wieczorek, Asian development pathways and sustainable sociotechnical regimes, Technological Forecasting \& Social Change 76(2009) 218228.

[5] D. Angel, M.T. Rock, Environmental rationalities and the development state in East Asia: prospects for a sustainability transition, Technological Forecasting \& Social Change 76(2) (2009) 229240. 
[6] M.T. Rock, J.T. Murphy, R. Rasiah, P. van Seters, S. Managi, A hard slog, not a leap frog: globalization and sustainability transitions in developing Asia, Technological Forecasting \& Social Change 76(2) (2009) 241254.

[7] X. Bai, A. Wieczorek, S. Kaneko, S. Lisson, A. Contreras, Enabling sustainability transitions in Asia: the importance of vertical and horizontal linkages, Technological Forecasting \& Social Change 76(2) (2009) 255266.

[8] K. Lee, C. Lim, Technological regimes, catching-up and leapfrogging: findings from the Korean industries, Research Policy 30(3) (2001) 459483.

[9] R. Perkins, Environmental leapfrogging in developing countries: a critical assessment and reconstruction, Natural Resources Forum 27(2003) 177188.

[10] K.S. Gallagher, Limits to leapfrogging in energy technologies? Evidence from the Chinese automobile industry, Energy Policy 34(4) (2006) 383394.

[11] A. Tukker, Leapfrogging into the future: developing for sustainability, International Journal of Innovation and Sustainable Development 1(1/2) (2005) 6584.

[12] L. Coenen, P. Benneworth, B. Truffer, Towards a spatial perspective on sustainability transitions, Research Policy (accepted)

[13] W.E. Steinmueller, ICTs and the possibilities for leapfrogging by developing countries, International Labour Review 140(2) (2001) 193210.

[14] K.J. Kumar, A.O. Thomas, Telecommunications and development: the cellular mobile "revolution“ in India and China, Journal of Creative Communications 1(3) (2006) 297309.

[15] Q. Mu. K. Lee, Knowledge diffusion, market segmentation and technological catch-up: the case of the telecommunication industry in China, Research Policy 34(6) (2005) 759783.

[16] J. James, Leapfrogging in mobile telephony: a measure for comparing country performance, Technological Forecasting and Social Change 76(7) (2009) 991998.

[17] J. Zhao, M.W. Melaina, Transition to hydrogen-based transportation in China: lessons learned from alternative fuel vehicle programs in the United States and China, Energy Policy 34(11) (2006) 12991309.

[18] K. Lee, Making a technological catch-up: barriers and opportunities, Asian Journal of Technology Innovation 13(2) (2005) 97120.

[19] J.I. Lewis, Technology acquisition and innovation in the developing world: wind turbine development in China and India, Studies in Comparative International Development 42(2007) 208232.

[20] J. van den Bergh, B. Truffer, G. Kallis, Environmental innovation and societal transitions: introduction and overview, Environmental Innovation and Societal Transitions 1(1) (2011) 123. 
[21] J. Markard, B. Truffer, Technological innovation systems and the multi-level perspective: towards an integrated framework, Research Policy 37(4) (2008) 596615.

[22] C. Freeman, Continental, national and sub-national innovation systemscomplementarity and economic growth, Research Policy, 31(2) (2002) 191211.

[23] B. Carlsson, Internationalization of innovation systems: a survey of the literature, Research Policy 35(1) (2006) 5667.

[24] M. Fromhold-Eisebith, Bridging scales in innovation policies: how to link regional, national and international innovation systems, European Planning Studies 15(2) (2007) 217 233.

[25] L. Coenen, B. Truffer, Editorial: places and spaces of sustainability transitions: geographical contributions to an emerging research and policy field, European Planning Studies (in press).

[26] B. Truffer, Society, technology, and region: contributions from the social study of technology to economic geography, Environment and Planning A 40(4) (2008) 966985.

[27] M. Maurer, D. Rothenberger, T.A. Larsen, Decentralised wastewater treatment technologies from a national perspective: at what costs are they competitive? Water Science and Technology 5(6) (2006) 145154.

[28] P.A. Wilderer, Some thoughts about future perspectives of water and wastewater management, Water Science and Technology 49(5-6) (2004) 3537.

[29] A.G. Fane, S.A. Fane, The role of membrane technology in sustainable decentralized wastewater systems, Water Science and Technology 51(10) (2005) 317325.

[30] IPCC, Climate Change 2007-Mitigation of Climate Change, Cambridge University Press, Cambridge, 2007.

[31] R. Sauter, J. Watson, Technology leapfrogging: a review of the evidence, University of Sussex, Sussex Energy Group, Science and Technology Policy Research (SPRU), 2008, p. 8.

[32] P.A. David, Clio and the Economics of QWERTY, American Economic Review 75 (1985) 332337.

[33] W. Brian Arthur, Y.M. Emoliev, Y.M. Kaniovski, Path-dependent processes and the emergence of macro-structure, European Journal of Operational Research 30(3) (1987) 294 303.

[34] D.P. Angel, M.T. Rock, T. Feridhanusetyawan, Toward clean shared growth in Asia, in: M.T. Rock, D.P. Angel (Eds.), Asia’s Clean Revolution: Industry, Growth and the Environment, Greenleaf, Sheffield, 2000.

[35] J. Revilla Diez, L. Schätzl, Regionale Innovationspotenziale und innovative Netzwerke in Ost- und Südostasien-theoretische und methodische Anmerkungen, Zeitschrift für Wirtschaftsgeographie 1 (2006) 316. 
[36] D. Wallace, Sustainable Industrialization, Earthscan, London, 1996.

[37] X. Liu, Path-following or leapfrogging in catching-up: the case of Chinese telecommunication equipment industry, Circle Electronic Working Paper Series 1 (2007) 1 36.

[38] C. Edquist, Reflections on the systems of innovation approach, Science and Public Policy 31(6) (2004) 485489.

[39] A. Bergek, S. Jacobsson, B. Carlsson, S. Lindmark, A. Rickne, Analyzing the functional dynamics of technological innovation systems: a scheme of analysis, Research Policy 37(3) (2008) 407429.

[40] B. Carlsson, S. Jacobsson, M. Holmen, A. Rickne, Innovation systems: Analytical and methodological issues, Research Policy 31(2) (2002) 233245.

[41] B. Lundvall, National systems of innovation - toward a theory of innovation and interactive learning, Pinter, London, 1992.

[42] C. Freeman, Technology and economic performance: lessons from Japan, Pinter, London, 1987.

[43] R. Nelson, National innovation systems: a comparative analysis, Oxford University Press, New York, 1993.

[44] F. Malerba, Sectoral systems of innovation: basic concepts, in: F. Malerba (Ed.), Sectoral Systems of Innovation: Concepts, Issues and Analyses of Six Major Sectors, Cambridge University Press, Cambridge, 2004.

[45] P. Cooke, M. Gomez Uranga, G. Etxebarria, Regional innovation systems: institutional and organisational dimensions, Research Policy 26(4-5) (1997) 475491.

[46] B. Carlsson, R. Stankiewicz, On the nature, function and composition of technological systems, Evolutionary Economics 1 (1991) 93118.

[47] S. Jacobsson, A. Johnson, The diffusion of renewable energy technology: an analytical framework and key issues for research, Energy Policy 28(9) (2000) 625640.

[48] A. Bergek, S. Jacobsson, The emergence of a growth industry: a comparative analysis of the German, Dutch and Swedish wind turbine industries, in: J.S. Metcalfe, U. Cantner (Eds.), Change, Transformation and Development, Physica-Verlag (Springer), Heidelberg, 2003.

[49] S. Jacobsson, A. Bergek, Transforming the energy sector: the evolution of technological systems in renewable energy technology, Industrial and Corporate Change 13(5) (2004) 815 849.

[50] M. Hekkert, R. Suurs, S. Negro, S. Kuhlmann, R. Smits, Functions of innovation systems: a new approach for analysing technological change, Technological Forecasting \& Social Change 74(4) (2007) 413432. 
[51] J. Markard, M. Stadelmann, B. Truffer, Prospective analysis of technological innovation systems: identifying technological and organizational development options for biogas in Switzerland, Research Policy 38 (2009) 655667.

[52] S. Jacobsson, A. Bergek, Innovation system analyses and sustainability transitions: contributions and suggestions for research, Environmental Innovation \& Societal Transitions 1(1) (2011) 4157.

[53] S.O. Negro, M.P. Hekkert, Explaining the success of emerging technologies by innovation system functioning: the case of biomass digestion in Germany, Technology Analysis \& Strategic Management 20(4) (2008) 465482.

[54] M.P. Hekkert, R. Harmsen, A. de Jong, Explaining the rapid diffusion of Dutch cogeneration by innovation system functioning, Energy Policy 35(9) (2007) 46774687.

[55] S. Jacobsson, V. Lauber, The politics and policy of energy system transformationexplaining the German diffusion of renewable energy technology, Energy Policy 34(3) (2006) 256276.

[56] H. Rohracher, B. Truffer, J. Markard, Doing institutional analysis of innovation systems: a conceptual framework. Paper presented at the DRUID summer conference, Copenhagen, 2009).

[57] W. Liu, P. Dicken, Transnational corporations and "obligated embeddedness": foreign direct investment in China's automobile industry, Environment and Planning A 38 (2006) 12291247.

[58] S. Amin, B. Pearce, Unequal development, Monthly Review Press, New York, 1976.

[59] R. Thorp, Progress, poverty and exclusion, Inter-American Development Bank, Washington, DC, 1998.

[60] D.D. Heckathorn, Respondent-driven sampling II: deriving valid estimates from chainreferral samples of hidden populations, Social Problems 49 (2002) 1134.

[61] J. Gläser, G. Laudel, Experteninterviews und qualitative Inhaltsanalyse als Instrumente rekonstruierender Untersuchungen, Verlag für Sozialwissenschaften, Wiesbaden, Germany, 2006.

[62] E. Friedler, R. Kovalio, N. Galil, On-site greywater treatment and reuse in multi-storey buildings, Water Science and Technology 51(10) (2005) 187194.

[63] M. Becker, S. Geisler, M. Hetschel, H. Hiessl, Dezentrale Abwasserentsorgung mit Kleinkläranlagen in Verantwortung eines Wasserwirtschaftsverbandes, Wasser Abwasser 48(6) (2007) 426430.

[64] S. Judd, C. Judd, The MBR book, Elsevier, Oxford, 2006.

[65] B. Lesjean, E.H. Huisjes, Survey of the European MBR market: trends and perspectives, Desalination 231(1-3) (2008) 7181. 
[66] X. Zheng, Y. Zhou, S. Chen, H. Zheng, C. Zhou, Survey of MBR market: Trends and perspectives in China, Desalination 250 (2010) 609612.

[67] Z. Wang, Z. Wu, S. Mai, C. Yang, X. Wang, Y. An, Z. Zhou, Research and applications of membrane bioreactors in China: progress and prospect, Separation and Purification Technology 62(2) (2008) 249263.

[68] C. Binz, B. Truffer, International technological innovation systems-A relational analysis of the innovation geography of membrane bioreactor technology, Paper presented at the 2010 GLOBELICS conference, Kuala Lumpur, 2010.

[69] X. Liang, M.P. van Dijik, Financial and economic feasibility of decentralized wastewater reuse systems in Beijing, Water Science and Technology 61(8) (2010) 19651973.

[70] X. Huang, K. Xiao, Y. Shen, Recent advances in membrane bioreactor technology for wastewater treatment in China, Frontiers of Environmental Science \& Engineering in China 4(3) (2010) 245270.

[71] G. Browder, S. Xie, Y. Kim, L. Gu, M. Fan, D. Ehrhardt, Stepping up: Improving the performance of China’s water utilities, The World Bank, Washington, DC, 2007.

[72] W. Yang, N. Cicek, J. Ilg, State-of-the-art of membrane bioreactors: worldwide research and commercial applications in North America, Journal of Membrane Science 270 (2006) 201 211.

[73] B. Lesjean, A. Tazi-Pain, D. Thaure, H. Moeslang, H. Buisson, Ten persistent myths and the realities of membrane bioreactor technology for municipal applications, Water Science and Technology 63(1) (2011) 3239.

[74] H. Gebauer, B. Truffer, E. Störmer, C. Binz, Capability perspective on business network formation: empirical evidences from wastewater treatment industry, European Business Review (in press).

[75] B. Truffer, C. Binz, H. Gebauer, E. Störmer, Success conditions for on-site technologies: a system innovation perspective, in: T. Larsen, K. Udert, J. Lienert (Eds.), Wastewater Management: Source Separation and Decentralisation, IWA Publishing, London, forthcoming.

[76] J. Revilla Diez, Metropolitan innovation systems: a comparison between Barcelona, Stockholm and Vienna, International Regional Science Review 25 (2002) 6385.

[77] M. Hu, J.A. Mathews, China's national innovative capacity, Research Policy 37(9) (2008) 14651479.

[78] B. Truffer, L. Coenen, Environmental innovation and sustainability transitions in regional studies, Regional Studies (accepted).

[79] R. Otterpohl, R. Braun, M. Oldenburg, Innovative technologies for decentralised water-, wastewater and biowaste management in urban and peri-urban areas, Water Science \& Technology 48(11-12) (2003) 2332. 


\section{Appendix}

Table appendix: Main field of competence of the interviewed experts

Main field of competence

Basic research in MBR technology

Applied research for MBR package plants

Transnational companies

Chinese engineering companies and MBR manufacturers

Chinese industrial and environmental associations / NGOs

Chinese design institutes and authorities

Chinese scientists investigating innovation and environmental policy

MBR package plant manufacturing companies (2 European, 1 Chinese)

Investment companies in the water sector
Number of interviews

5

4

5

3

2

2

5

3 